\title{
De opkomst van private verhuur in Nederland: woningnood als winst
}

\author{
Barend Wind ${ }^{*}$
}

\section{De opkomst van de private verhuur}

Sinds de Tweede Wereldoorlog wordt de Nederlandse woningmarkt gedomineerd door twee sectoren: de sociale-huursector en de koopsector. Beide sectoren konden sterk groeien ten opzichte van de private huursector omdat ze een dominante rol speelden tijdens de wederopbouwperiode (1945-1960) en omdat huisjesmelkerij grotendeels werd uitgebannen tijdens sloop-/nieuwbouwoperaties in oude stadswijken in het kader van stadsvernieuwing (1970-1990) (Van Kempen \& Priemus, 2002). Ongemerkt is de private huursector de laatste tien jaar echter flink in opkomst. In de grote steden is de private huursector tussen 2006 en 2016 zelfs met 30 procent gegroeid. In Utrecht en Den Haag zijn inmiddels drie op de tien woningen in handen van private verhuurders. In dezelfde periode is het aantal privépersonen dat een woning koopt om te verhuren zelfs met 75 procent toegenomen. Toch zijn de ontwikkelingen op de private huurmarkt grotendeels onopgemerkt gebleven. Andere woningmarktvraagstukken, zoals de dalende woningprijzen in de jaren na de economische crisis van 2008, de onbetaalbaarheid van (koop)woningen in de periode daarna, de huidige woningnood in de grote steden en de toenemende sociale segregatie, sprongen meer in het oog (Haffner \& Boumeester, 2015; Hochstenbach \& Musterd, 2018). De opkomst van de private verhuur is deels het gevolg van de bovengenoemde ontwikkelingen, maar in toenemende mate ook de oorzaak ervan.

Onlangs verscheen een rapport van de hand van onderzoekers Aalbers e.a. (2018) waarin de activiteiten van private verhuurders in Nederland in kaart worden gebracht. Het is een dappere poging om het debat over de toekomst van de private huursector aan te zwengelen, gebaseerd op een stevige probleemanalyse. De meerwaarde van hun onderzoek is de relatie die de auteurs leggen tussen het woonbeleid dat Nederland in de laatste jaren gevoerd heeft, en de uitkomsten voor de verhoudingen op de woningmarkt. In dit artikel zal ik de resultaten van het voornoemde onderzoek bespreken, geillustreerd aan de hand van mijn eigen ervaringen op de Amsterdamse woningmarkt. Vervolgens zal ik de resultaten in een internationaal vergelijkend perspectief plaatsen. In verschillende Europese landen speelt de private huursector een heel andere rol in de woningmarkt, wat van invloed is op de beschikbaarheid en betaalbaarheid van het wonen in de stad. Bovendien zijn de huurinkomsten voor huisbazen in sommige landen verweven met de verzorgingsstaat: voor de een is het een pensioenvoorziening, voor de

* Dr. Barend Wind is universitair docent sociale planologie bij de Basiseenheid Planologie, faculteit Ruimtelijke wetenschappen van de Rijksuniversiteit Groningen. 
ander een speculatieve belegging. Door de reflectie op omvang en aard van de private verhuur in Nederland, en de positionering van de Nederlandse praktijk in de Europese context, zijn er drie vragen te beantwoorden. Wat voor nieuwe vormen van ongelijkheid ontstaan er door de opkomst van de private huursector? Op basis van welke argumenten kan private verhuur geproblematiseerd worden? In hoeverre zijn de beleidsvoorstellen die Aalbers e.a. doen in hun rapport in staat om de beschikbaarheid en de betaalbaarheid van het wonen te vergroten, zonder de bestaanszekerheid aan te tasten van verhuurders voor wie de huurinkomsten een vorm van (sociale) zekerheid vormen?

\section{De sociale en ruimtelijke dynamiek van de private verhuur}

Het rapport van Aalbers e.a. concludeert dat de private huursector terug is van weggeweest, en dat dit de uitkomst is van een kwantitatieve en kwalitatieve herstructurering van deze sector. De kwantitatieve herstructurering omvat de groei van het aantal woningen dat in dit segment wordt aangeboden. De kwalitatieve herstructurering behelst de verschuiving van het aanbod in de particuliere huurvoorraad van het gereguleerde segment (onder $€ 711$ per maand) naar de zogeheten vrije sector (boven $€ 711$ per maand). De auteurs van het rapport wijzen op vier - met elkaar verweven - mechanismen die deze herstructurering op gang gebracht hebben.

Ten eerste heeft de verkoop van corporatiewoningen aan beleggers de voorraad private huurwoningen flink vergroot. Het bekendste voorbeeld is de verkoop van een deel van de portefeuille van de Rotterdamse corporatie Vestia, hetgeen nodig was om de financiële verliezen van vastgoedspeculatie in de aanloop naar de economische crisis van 2008 op te vangen (Aalbers, Loon, van \& Fernandez, 2017).

Ten tweede is het aantal woningen dat gekocht wordt om te verhuren (buy-to-let) flink gestegen (tussen 2012 en 2016 met 75 procent). Starters op de woningmarkt zullen hier niet verbaasd van opkijken. Zelf heb ik begin 2017 geprobeerd een betaalbaar appartement te kopen in Amsterdam. Met mijn startersbudget was ik aangewezen op het onderste segment in de markt voor koopwoningen in Amsterdam ( $€$ 175.000-225.000). Tijdens de bezichtigingen van gestripte voormalige corporatiewoningen in noordelijke buitenwijken of van verloederde koopappartementen van onlangs overleden pioniers van de wederopbouwwijken in Nieuw-West kwam ik uiteraard medestarters tegen. Echter, net zo in het oog springend waren de ouders die zo een appartement wilden aanschaffen voor hun studerende kinderen, verhuurmakelaars die het wilden kopen en verhuren aan expats, of speculanten die geïnteresseerd waren in de woning als 'verhuurobject'. De verhuurders in spe hebben het gemakkelijk. Terwijl mijn bod beperkt wordt door het maximale hypotheekbedrag van de bank, hebben de toekomstige verhuurders vaak meer financiële armslag. Ze gebruiken hiervoor de overwaarde van hun (afbetaalde) eerste woning, of gebruiken bedrijfskapitaal om de woning te verwerven. Het Kadaster heeft becijferd dat bijna 20 procent van de in 2017 verkochte woningen in Amsterdam langs deze weg in handen is gekomen van ver- 
huurders. Echter, in het onderste segment van de woningmarkt is dit aandeel veel hoger (Kadaster, 2017). Dit drijft de prijzen op, waardoor een koopwoning voor veel starters en huishoudens met een lager inkomen niet meer binnen handbereik is (Paccoud, 2017). Uiteindelijk is het me gelukt: ik heb voor twee ton een klein driekamerappartement in Vogelaarwijk, Slotermeer bemachtigd. Sinds ik er woon, ontvang ik wekelijks brieven van investeringsmaatschappijen die mijn woning willen kopen - om te verhuren wel te verstaan. Het Parool kopte op 12 april 2018 dat de Amsterdamse woningmarkt om deze reden 'droogkookt'. Wanneer huishoudens elders een nieuwe woning kopen, gaan ze hun oude woning zelf verhuren of verkopen ze hun oude stek aan een investeerder.

Ten derde is de private huurmarkt gegroeid door de focus op 'middeldure' huurwoningen in de nieuwbouw. Waar sinds de jaren tachtig de bouw van koopwoningen is gepropageerd op basis van de ideologie dat kopers meer verantwoordelijkheid zouden nemen voor hun leefomgeving en een koopwoning bij zou dragen aan vermogensopbouw (Ronald, 2008), is sinds de economische crisis van 2008 het bouwen van private huurwoningen in zwang geraakt. Dit beleid speelt in op een groeiende groep huishoudens die tussen de wal en het schip valt: zij die niet meer in aanmerking komen voor een sociale-huurwoning sinds de inkomenseisen zijn aangescherpt, maar ook geen hypotheek kunnen krijgen omdat hun inkomen (1) te laag of (2) instabiel is. Nederland is al geruime tijd koploper in Europa wat betreft het aandeel mensen in de beroepsbevolking die geen vast contract heeft: ze werken (noodgedwongen) als zelfstandige zonder personeel (zzp'er) of uitzendkracht of in een tijdelijke functie (Dol, Boumeester \& Mariën, 2014). Hoewel de liberalisering van de arbeidsmarkt en de stimulering van het eigenwoningbezit zijn geworteld in een vergelijkbaar individualistisch ideaal, bijt het arbeidsmarktbeleid het volkshuisvestingsbeleid in de staart. Door de flexibilisering van de arbeidsmarkt kunnen juist steeds minder mensen zich een eigen woning veroorloven. Het inzetten op de uitbreiding van het aantal private huurwoningen in nieuwbouwprojecten is dan een doekje voor het bloeden. Een saillant detail is dat dezelfde woningen als koopwoningen lagere maandelijkse kosten met zich zouden brengen door een combinatie van hypotheekrenteaftrek (hetgeen de maanlasten voor kopers verlaagt) en hoge winstmarges voor verhuurders (hetgeen de maandlasten voor huurders weer verhoogt). In het rapport laten Aalbers e.a. (2018) zien dat de uitbreiding van de private huursector een duidelijk geografisch patroon kent. In Amsterdam is de private huursector sterk gegroeid in herstructureringsgebieden en in de gentrificatiewijken, waar de stijging van de woningprijzen heeft geleid tot het liberaliseren van de huren.

Ten slotte is de groei van de private huurmarkt te wijten aan de liberalisering van een steeds groter deel van de huurmarkt. Sinds 2015 speelt de WOZ-waarde (waardering onroerende zaken) een belangrijke rol in het woningwaarderingsstelsel voor gereguleerde huurwoningen. Het puntenaantal bepaalt bovendien de grens waarboven de huur vrijelijk door de verhuurder mag worden bepaald. In gebieden met een hoge druk op de woningmarkt is door deze maatregel een steeds groter gedeelte van de voorraad huurwoningen geliberaliseerd. Waar 
schaarste heerst en het marktmechanisme de prijs bepaalt, wordt het wonen duurder. Het is de overheid zelf die deze situatie in de hand werkt door een steeds groter gedeelte van de woningzoekenden deze sector in te drukken. De verhuurders zijn spekkoper, terwijl de huurders de rekening betalen. Zo bezien is het geen wonder dat zo veel individuele investeerders en internationale beleggers zich op deze groeimarkt begeven.

\section{Woonvermogensongelijkheid en de welvaartsstaat}

Sinds de neoliberale doctrine eind jaren tachtig politiek ingang vond in WestEuropa, en financiële, arbeids- en woningmarkten werden geliberaliseerd, staatsbedrijven en maatschappelijke diensten werden geprivatiseerd en werknemers werden onderworpen aan internationale concurrentie, is een nieuwe vorm van ongelijkheid steeds belangrijker geworden: vermogensongelijkheid (Spilerman, 2000). Steeds vaker bepaalt het vermogen van huishoudens (en niet zozeer inkomen) levenskansen.

De toename van (het belang van) vermogensongelijkheid kan niet los worden gezien van de ontwikkelingen op de woningmarkt. Ten eerste is woonvermogen (de marktwaarde van de woning minus hypotheekschuld) de belangrijkste bron van vermogen voor het grootste deel van de Nederlandse huishoudens. Ten tweede laat Piketty (2014) in zijn analyses zien dat de toename van vermogen relatief tot het nationaal inkomen vrijwel geheel is toe te schrijven aan de toename van het woonvermogen. De analyses waarop mijn proefschrift gebaseerd is, tonen aan dat de toename van de woonvermogensongelijkheid is toe te schrijven aan de stimulering van het eigenwoningbezit door middel van de liberalisering van de hypotheek- en huizenmarkt. Dat heeft de leencapaciteit vergroot, waardoor meer huishoudens toegang hebben gekregen tot een (via schuld gefinancierde) koopwoning. Omdat tegelijkertijd meer personen bieden op dezelfde woningvoorraad, zijn de prijzen opgedreven. Zij die de markt vroeg hebben betreden, hebben flinke vermogenswinsten geboekt.

Onderzoek laat zien dat winsten en verliezen op de liberale woningmarkt niet alleen ongelijk over de generaties verdeeld zijn, maar vooral ook tussen sociale klassen (Wind, Lersch \& Dewilde, 2017). Ten eerste zorgen gecompliceerde hypotheekproducten als 'aflossingsvrije' hypotheken ervoor dat vooral kopers in de lagere sociaaleconomische groepen nauwelijks vermogen opbouwen. Ten tweede is hun overwaarde absoluut én relatief kleiner dan die van huishoudens in de hogere sociaaleconomische strata. In de afgelopen decennia zijn zowel huishoudens met een kleine beurs als grootverdieners meer geclusterd komen te wonen. De prijsstijgingen in de buurten waar de hogere sociaaleconomische groepen terecht zijn gekomen, zijn veel geprononceerder geweest (Wind \& Hedman, 2017). Door de bank genomen betekent dit dat vooral oudere huishoudens met een hoge sociaaleconomische status veel woonvermogen hebben, dat ze vervolgens in (kunnen) zetten om tweede woningen te kopen: soms als vakantiehuis, meestal als verhuurobject (voor studerende kinderen of hun generatiegenoten 
met een lager opleidingsniveau en dito salaris). Hun koopkracht brengt de woningprijzen op zo'n hoog peil dat veel starters de markt niet kunnen betreden. De woningprijsinflatie die ze zelf teweegbrengen, komt vervolgens ten goede aan de zittende kopers. Waar de overheid eerst de woningmarkt stimuleerde vanuit het geloof dat hogere woningprijzen voor een grote groep woningeigenaren uit de middenklasse konden compenseren voor stagnerende inkomens, heeft datzelfde beleid nu als gevolg dat vermogen zich concentreert aan de top - bekostigd door de hoge huren die de brede middenklasse aan hen betaalt in afwezigheid van betaalbare koop- of sociale-huurwoningen.

Er bestaat een verband tussen de organisatie van de woningmarkt en de organisatie van de verzorgingsstaat. Door volkshuisvestingsonderzoekers wordt wel eens gesproken over een afruil tussen eigenwoningbezit en pensioenen (Castles, 1998). Het mechanisme hier is eenvoudig: voor jonge huishoudens concurreert het aflossen van de hypotheek met het betalen van hoge belastingen en sociale premies, terwijl een afbetaalde koopwoning voor oudere huishoudens de noodzaak van een groot pensioen verkleint, aangezien de woonlasten laag zijn. Dit wordt ook wel homeownership-based welfare genoemd. Landen met een grote huursector zouden daarom hoge pensioenen hebben, terwijl pensioenen magerder zijn in landen met veel eigenwoningbezit. Een blik op Nederland laat zien dat dit niet altijd opgaat: ons land heeft een uitgebreid pensioensysteem (met verplichte deelname) en een behoorlijk grote koopsector (met hoge hypotheekschulden). In de landen waar de liberalisering van financiële markten geresulteerd heeft in beschikbaarheid van geavanceerde hypotheekproducten, is actief asset-based welfare ontstaan waar op micro- of macroschaal het woonvermogen wordt gebruikt als de pensioenpot (Ronald, Lennartz \& Kadi, 2017).

Niet alle beroepsgroepen worden even goed beschermd door de verzorgingsstaat. In de conservatief-corporatistische verzorgingsstaten (de Duitstalige landen, Frankrijk, België) krijgen kleine zelfstandigen alleen een basispensioen. Om in hun oude dag te voorzien moeten ze het heft in eigen hand nemen (Dewilde \& Raeymaeckers, 2008). Het is opvallend dat in de conservatief-corporatistische verzorgingsstaten kleine zelfstandigen vaak een tweede woning kopen en deze verhuren om inkomsten te genereren na hun pensionering. De gereguleerde huren in deze landen zorgen voor een niet al te hoog maar wel stabiel rendement, waardoor het uitermate geschikt is als pensioenvoorziening. Het feit dat een deel van de bevolking niet gedekt is door de welvaartsstaat, zorgt er dus voor dat zij die wel sociale bescherming genieten, kunnen huren op de gereguleerde huurmarkt. In Nederland neemt het aantal zzp'ers in rap tempo toe. De toekomst zal leren in hoeverre zij pensioen op zullen bouwen. In de Angelsaksische wereld is het tweedewoningbezit - en met name investeren in huurwoningen - om een heel andere reden in zwang geraakt in de laatste vijftien jaar.

Terwijl in de conservatief-corporatistische landen de woningprijzen nauwelijks stegen door beperkte kredietverstrekking en huurregulering, zijn de woningprijzen in de Angelsaksische landen ontploft onder invloed van de liberalisering van de hypotheekmarkt. Net als in Nederland hebben jongeren en huishoudens 
met middeninkomens hierdoor nauwelijks meer toegang tot een koopwoning. Huishoudens die hun woning inmiddels afbetaald hebben, en veel woonvermogen hebben opgebouwd door de prijsstijgingen, profiteren van deze situatie: zij hebben toegang tot hypothecair krediet en kunnen hun woning verhuren voor een hoge prijs op de ongereguleerde huurmarkt (Gardiner, 2017). Let wel: de groep die geen hypotheek krijgt van de bank omdat het uitgeven van zo'n groot deel van het inkomen als onverantwoord wordt beschouwd, mag een hoger bedrag nu wel uitgeven aan huur. De vermogensopbouw onder huisbazen in zogenaamde liberale welvaartsstaten is, in tegenstelling tot in de conservatief-corporatistische welvaartsstaten, geen verzorgingsstaatarrangement. Het is geen aanvulling op een matig pensioen, maar een generieke investering.

\section{Buy-to-let beteugelen}

Nederland lijkt meer op het Verenigd Koninkrijk dan op Duitsland wat betreft aard van de buy-to-let-sector. In plaats van een investering in gereguleerde huurwoningen als pensioenvoorziening (zoals in Duitsland) is een tweede woning in Nederland vaak een investering in een huurwoning in de vrije sector voor hen die al een genereus pensioen hebben (zoals in het Verenigd Koninkrijk). In ons land is de opkomst van de buy-to-let-sector het gevolg van een steeds grotere concentratie van woonvermogen, maar ook de oorzaak van de toenemende vermogensongelijkheid. Minister Kajsa Ollongren (D66) is tamelijk positief over deze ontwikkeling. Zij stelt dat 'buy to let [kan] bijdragen aan een wenselijke verruiming van het aanbod huurwoningen, met name wanneer die verruiming plaatsvindt in het nog relatief kleine middenhuursegment'. Dit is ironisch, aangezien de buy-to-letmarkt in toenemende mate bestaat uit dure huurwoningen in plaats van middeldure huurwoningen. De woningen die wél in het middenhuursegment vallen, waren vaak voordien goedkope koopwoningen of betaalbare corporatiewoningen. Alles tezamen lijkt een versterking van de private huurmarkt, en de buy-to-letsector in het bijzonder, vooral bij te dragen aan stijgende woningprijzen en een verdere concentratie van vermogen.

Aalbers e.a. (2018) doen een twaalftal beleidsvoorstellen om de buy-to-let-sector te reguleren. De kracht van hun voorstellen is gelegen in het feit dat ze betrekking hebben op de woningmarkt als geheel. Door de markt als geheel meer te reguleren wordt de aantrekkelijkheid van buy-to-let voor investeerders verminderd en kunnen nieuwe coalities voor betaalbare woningbouw ontstaan. De belangrijkste voorstellen hebben betrekking op de gereguleerde huursector: het verhogen van de maximale inkomensgrens om in aanmerking te komen voor een sociale-huurwoning en een hervorming van het woningwaarderingsstelsel (de WOZ-waarde eruit, nieuwe criteria erin om een groter deel van de markt te reguleren). Andere voorstellen hebben betrekking op de koopsector: het invoeren van een kettingbeding over de maximale huurprijs na privatisering van corporatiewoningen, het invoeren van een zelfbewoningsclausule bij nieuwbouw en het verhogen van de overdrachtsbelasting (behalve voor starters). 
Willen we meer (zoals minister Ollongren) of minder buy-to-let in Nederland? Met hun voorstellen stellen Aalbers, Bosma, Fernandez en Hochstenbach 'minder, minder, minder'. Op basis van de ontwikkelingen op onze woningmarkt is deze wens meer dan gerechtvaardigd.

Goed woonbeleid kan in mijn ogen afgemeten worden aan drie criteria: in hoeverre (1) er betaalbare koop- en huurwoningen voor alle inkomensgroepen beschikbaar zijn, (2) er vermogen kan worden opgebouwd door verschillende inkomensgroepen, en (3) verschillende sociale groepen kunnen kiezen voor een gemengde, leefbare buurt. De voorstellen van Aalbers e.a. dragen hier zeker aan bij. Een blik over de grens (Duitsland) leert dat de particuliere huursector, en kleinschalige buy-to-let-activiteiten, bij kunnen dragen aan de bovenstaande doelen, mits de sector goed gereguleerd is. Met een oog op de Nederlandse woningmarkt bestaat een deel van de sector uit intergenerationele solidariteit. Ouders kopen een woning voor hun zoon of dochter die zich geen huurwoning in de vrije sector of koopwoning kan veroorloven. We mogen ervan uitgaan dat deze ouders hun woning niet voor vrije-sectortarieven verhuren. Hun activiteiten worden daarom niet geraakt door een uitbreiding van de huurregulering. Wél worden hun activiteiten geraakt door een zelfbewoningsclausule. Een uitzondering voor betaalbare verhuur ligt daarom voor de hand.

Door de flexibilisering van de arbeidsmarkt ligt de verhuismobiliteit hoger en wordt het verkrijgen van een hypotheek steeds moeilijker. Het is daarom niet per se erg dat het eigenwoningbezit afneemt, mits hiervoor betaalbare huurwoningen terugkomen. Onder de huidige regulering is dit niet het geval, onder de voorstellen van Aalbers e.a. (2018) wel. De opkomst van flexibele arbeidsverhoudingen (zoals zzp) waardoor werknemers minder pensioen opbouwen, vergroot de noodzaak tot vermogensopbouw om inkomen te genereren na pensionering. Het kopen en verhuren van één of enkele huurwoningen kan hieraan bijdragen. Duitsland laat zien dat het voor deze groep belangrijker is om stabiele huurinkomsten te kunnen verwachten dan dat de onderliggende waarde explosief toeneemt, hetgeen het hoofddoel van (internationale) beleggers lijkt te zijn. Het ligt daarom voor de hand om regelgeving te differentiëren aan de hand van de omvang van de vastgoedportefeuille van de verhuurder om verschil te maken tussen speculatieve investeerders en kleinschalige huisbazen.

De huidige laisser-faire benadering van de private huursector leidt tot een snelle groei van buy-to-let, exorbitant hoge huren en kapitaalaccumulatie in een tijd waarin juist starters groepen met lage- en middeninkomens afhankelijk zijn van een betaalbare huurwoning, en bovendien vermogen nodig hebben om eventuele financiële tegenslagen op te vangen. Regulering is daarom hard nodig. Hoewel de voorstellen die Aalbers cum suis doen om de buy-to-let-sector van rijkswege te reguleren bijzonder effectief zullen zijn, is de kans groot dat echte verandering sterk afhankelijk zal zijn van de lagere overheden. Zij kunnen op korte termijn ingrijpen op zowel de aanbod- als de vraagkant door een vergunningensysteem voor verhuur in te voeren en de druk van de private huurmarkt te halen door het bouwen van sociale (studenten)woningen te stimuleren. 


\section{Literatuur}

Aalbers, M.B, Bosma, J., Fernandez, R., \& Hochstenbach, C. (2018). Buy-to-let gewikt en gewogen. https://ees.kuleuven.be/geography/projects/refcom/huuronderzoek/buy-tolet.pdf, geraadpleegd op 28 mei 2018.

Aalbers, M.B., Loon, J. van, \& Fernandez, R. (2017). The financialization of a social housing provider. International Journal of Urban and Regional Research, 41 (4): 572-587.

Castles, F.G. (1998). The really big trade-off: Home ownership and the welfare state in the new world and the old. Acta politica, 33: 5-19.

Dewilde, C., \& Raeymaeckers, P. (2008). The trade-off between home-ownership and pensions: individual and institutional determinants of old-age poverty. Ageing \& Society, 28 (6): 805-830.

Dol, K., Boumeester, H., \& Mariën, G. (2014). De positie van flexwerkers en ZZP-ers op de woningmarkt. Delft: Delft University of Technology, OTB Research for the Built Environment.

Gardiner, L. (2017). Home Sweet Home - The Rise of Multiple Property Ownership in Britain. www.resolutionfoundation.org/media/blog/homes-sweet-homes-the-rise-ofmultiple-property-ownership-in-britain/, geraadpleegd op 23 mei 2018.

Haffner, M., \& Boumeester, H. (2015). Housing affordability in the Netherlands: The impact of rent and energy costs. Journal of Housing and the Built Environment, 30 (2): 293-312.

Hochstenbach, C., \& Musterd, S. (2018). Gentrification and the suburbanization of poverty: changing urban geographies through boom and bust periods. Urban Geography, 39 (1): 26-53.

Kadaster (2017). Particulieren kopen steeds vaker woningen om te verhuren. www.kadaster.nl/ -/particulieren-kopen-steeds-vaker-woningen-om-te-verhuren, geraadpleegd op 28 mei 2018.

Kempen, R. van, \& Priemus, H. (2002). Revolution in social housing in the Netherlands: possible effects of new housing policies. Urban Studies, 39 (2): 237-253.

Nul20 (2017). Buy-to-let grijpt om zich heen. www.nul20.nl/dossiers/buy-let-grijpt-om-zichheen, geraadpleegd op 28 mei 2017.

Paccoud, A. (2017). Buy-to-let gentrification: Extending social change through tenure shifts. Environment and Planning A, 49 (4): 839-856.

Parool (2018). Amper huizen te koop: Amsterdammer verhuurt liever. www.parool.nl/ amsterdam/amper-huizen-te-koop-amsterdammer-verhuurt-liever a4570643, geraadpleegd op 28 mei 2018.

Piketty, T. (2014). Capital in the 21st Century . Harvard: Harvard University Press.

Ronald, R. (2008). The ideology of home ownership: Homeowner societies and the role of housing . Springer.

Ronald, R., Lennartz, C., \& Kadi, J. (2017). What ever happened to asset-based welfare? Shifting approaches to housing wealth and welfare security. Policy \& Politics, 45 (2): 173-193.

Spilerman, S. (2000). Wealth and stratification processes. Annual Review of Sociology, 26 (1): 497-524.

Wind, B., \& Hedman, L. (2017). The uneven distribution of capital gains in times of sociospatial inequality: Evidence from Swedish housing pathways between 1995 and 2010. Urban Studies (Online First).

Wind, B., Lersch, P., \& Dewilde, C. (2017). The distribution of housing wealth in 16 European countries: Accounting for institutional differences. Journal of Housing and the Built Environment, 32 (4): 625-647. 